University of Nebraska - Lincoln

DigitalCommons@University of Nebraska - Lincoln

Publications, Agencies and Staff of the U.S.

Department of Commerce

U.S. Department of Commerce

2010

Effects of Spatial Pattern and Economic Uncertainties on

Freshwater Habitat Restoration Planning: A Simulation Exercise

Aimee $\mathrm{H}$. Fullerton

NOAA Fisheries, Aimee.Fullerton@noaa.gov

E. Ashley Steel

NOAA Fisheries

lan Lange

University of Stirling

Yuko Caras

King County Department of Natural Resources and Parks

Follow this and additional works at: https://digitalcommons.unl.edu/usdeptcommercepub

Part of the Environmental Sciences Commons

Fullerton, Aimee H.; Steel, E. Ashley; Lange, lan; and Caras, Yuko, "Effects of Spatial Pattern and Economic Uncertainties on Freshwater Habitat Restoration Planning: A Simulation Exercise" (2010). Publications, Agencies and Staff of the U.S. Department of Commerce. 266.

https://digitalcommons.unl.edu/usdeptcommercepub/266

This Article is brought to you for free and open access by the U.S. Department of Commerce at DigitalCommons@University of Nebraska - Lincoln. It has been accepted for inclusion in Publications, Agencies and Staff of the U.S. Department of Commerce by an authorized administrator of DigitalCommons@University of Nebraska - Lincoln. 


\title{
Effects of Spatial Pattern and Economic Uncertainties on Freshwater Habitat Restoration Planning: A Simulation Exercise
}

\author{
Aimee H. Fullerton, ${ }^{1,2}$ E. Ashley Steel, ${ }^{1}$ Ian Lange, ${ }^{3}$ and Yuko Caras ${ }^{4}$
}

\begin{abstract}
Evaluating alternative future scenarios using simulation models is an emerging approach to conservation planning over large spatial and temporal extents. Such an approach is useful when predictions cannot be validated empirically; however, evaluating the sensitivity of scenario-based approaches to key uncertainties is necessary so that managers understand how real-world constraints might impact results. We used a simulation approach to investigate the sensitivity of freshwater habitat restoration plans to spatial pattern (e.g., project locations) and economic uncertainties (e.g., budget level and project costs) in a case study on Pacific salmon in the Lewis River Basin (WA, U.S.A.). We found that some evaluation metrics performed better when restoration was distributed randomly, whereas
\end{abstract}

others improved more when restoration occurred on contiguous stretches of river. Subwatersheds responded differently to restoration, suggesting that intrinsic characteristics limit restoration potential. Changes in budget usually caused proportionate improvements in habitat but disproportionate fish responses, suggesting a cumulative benefit for fish. Most per-dollar benefits increased as project cost decreased; therefore, model predictions are sensitive to project cost. Simulation analyses provided increased information about how economics and spatial pattern might affect habitats and salmon; these insights can help policymakers identify an appropriate restoration strategy.

Key words: decision analysis, land management, land use, landscape ecology, Pacific salmon, watershed.

\section{Introduction}

Habitat degradation has been indicated as a leading cause in species declines worldwide (e.g., Chan et al. 2007; Storch 2007; Goulson et al. 2008); therefore, habitat restoration has become a prominent approach for recovery of endangered species (Haines et al. 2006; Prather et al. 2008; Roni et al. 2008). Approximately $\$ 1$ billion was spent annually on river restoration in the United States since 1990 (Bernhardt et al. 2005), much of which was intended to improve freshwater habitat used by federally listed species. Restoration budgets are often uncertain from year to year, and can come with restrictions. Habitat restoration is constrained by landowner cooperation, the quality of grant proposals, project cost (i.e., costly projects are funded less frequently; Katz et al. 2007), and political motivation to fund projects. These limitations have often required that projects be chosen opportunistically, which may not be the most efficient habitat recovery strategy.

\footnotetext{
${ }^{1}$ Northwest Fisheries Science Center, NOAA Fisheries, 2725 Montlake Blvd East, Seattle, WA 98112, U.S.A.

2 Address correspondence to A. H. Fullerton, email Aimee.Fullerton@ noaa.gov

${ }^{3}$ Department of Economics, University of Stirling, Stirling, FK9 4LA, U.K

${ }^{4}$ King County Department of Natural Resources and Parks, 201 S Jackson Street,

Suite 706, Seattle, WA 98104, U.S.A

(C) 2010 Society for Ecological Restoration International

doi: 10.1111/j.1526-100X.2009.00620.x
}

Given that the effects of actions taken now will not be seen for many years, and because past restoration has been inadequately monitored (Bernhardt et al. 2005; Katz et al. 2007; Roni et al. 2008), it is difficult to evaluate possible management strategies empirically. Managers need tools for prioritizing those projects that are likely to have the greatest success, given economic and spatial constraints.

An increasingly popular approach in conservation planning is the use of scenarios to forecast effects of alternative management scenarios (Peterson et al. 2002). Using this framework, investigators have evaluated potential impacts from a variety of sources over large spatial scales (e.g., Ogden et al. 1999; Baker et al. 2004; Cumming 2007), including climate change (Battin et al. 2007), harvest strategies (Punt et al. 2001), and land management (Santelmann et al. 2004; Prato 2005). Spatially explicit scenario-planning can predict what set of watershed restoration projects will provide the greatest improvement when funding is limited (DeAngelis et al. 1998; Sklar et al. 2001).

The spatial allocation of restoration actions should influence their impact on aquatic habitats and associated biota. There is extensive literature on the presence of spatial patterns in landscape conditions, land use, and species distributions (e.g., Dobson et al. 1997; Spies et al. 2007), and on the importance of connectivity of essential habitats for species 
persistence (e.g., Crooks \& Sanjayan 2006). Many have considered factors contributing to optimal spatial designs for conservation reserve areas (Haight et al. 2002; Villa et al. 2002; Siitonen et al. 2003). However, little is published about how the spatial arrangement of habitat restoration projects may influence their effectiveness in river networks. Synergistic benefits (or antagonistic interactions) may exist when projects are located in close proximity (e.g., Newbold et al. 2005), and surrounding conditions may limit benefits produced by isolated restoration projects. These scaling-up ideas have rarely been evaluated systematically. Most evaluations of river restoration effectiveness are concerned with single projects, rather than with watershed- or population-level responses to multiple projects and their spatial arrangement (Bernhardt et al. 2005; Roni et al. 2008).

Economic constraints and uncertainties must also be considered when designing landscape-scale restoration plans (Merrifield 1997; Ferraro 2003). Management plans that consider only ecological objectives without also considering economic constraints may not be cost-effective (Ando et al. 1998; Haight et al. 2002; Waetzold et al. 2006). Conversely, funding for projects is often dispensed through competitive grants which may have little in common with ecological improvement objectives (Song \& M'Gonigle 2001). Conservation plans often are not implemented because they do not adequately address both economic and ecological metrics (Naidoo et al. 2006), and faith in purely technical analyses wanes without estimates of societal impacts (Lackey 1998).

Steel et al. (2008) developed a spatially explicit decisionsupport framework to evaluate the effect of alternative watershed management scenarios (i.e., suites of habitat restoration actions) on freshwater habitat improvements and Pacific salmonid population responses in the Lewis River Basin (Southwest Washington State, U.S.A.) (Fig. 1). For each scenario, the authors modeled the effect of restoration actions on key watershed processes including the delivery of water, sediment, and wood to stream channels to predict future instream conditions (Fig. 2). They then modeled species-specific responses of salmonids to the changes in-stream habitat. The combination of predicted changes in both habitat conditions and fish responses facilitated robust comparisons among management scenarios; however, their analyses did not address the spatial distribution of restoration actions or the impacts of economic uncertainties.

In this study, we use the suite of ecological models described by Steel et al. (2008) to evaluate spatial and economic factors that could affect the choice of restoration projects adopted into a management strategy. Our analyses do not focus on the specific scenarios described in Steel et al. (2008), but rather on more general patterns. Specifically, our scenarios ask (1) How do ecological benefits from restoration depend on local characteristics in the watershed? (2) Is there a benefit to conducting restoration projects on contiguous stream reaches (or road segments), or does a random spatial distribution of projects provide equal benefits? (3) How does budget size relate to cost-effectiveness? and (4) How much more or less could be improved if project costs changed?
We conducted simulations to evaluate how sensitive ecological predictions were to each of these questions.

\section{Methods}

\section{Study Area}

We conducted analyses in the Lewis River Basin, a tributary to the Columbia River, U.S.A. (Fig. 1). The basin encompasses $2,760 \mathrm{~km}^{2}$ and drains the western slope of the Cascade Mountain range $(5,974 \mathrm{~km}$ of streams on a $1: 24,000$ map, $1,082 \mathrm{~km}$ of which were potentially accessible to anadromous salmonids historically). Average annual precipitation in the lower watershed is approximately $200 \mathrm{~cm}$ (LCFRB 2004). The basin is relatively undeveloped, with the majority of the population concentrated in Woodland, Washington near the mouth of the river. Past disturbances in the watershed (located primarily in the forested upper part of the basin) have included stand-replacement fires, logging, and volcanic activity. Land use in the lower portion of the watershed is dominated by patchy agriculture and low-density residential, and gravel mining occurs in the lower East Fork. Four species of anadromous salmonids found in the watershed are listed under the Endangered Species Act: Oncorhynchus tshawytscha (Chinook salmon), O. kisutch (coho salmon), and $O$. keta (chum salmon), and O. mykiss (steelhead trout). Three large dams on the North Fork of the Lewis River are currently impassable to anadromous fish: Merwin Dam (river km 31), Yale Dam (river km 55), and Swift Dam (river $\mathrm{km}$ 77). Provisions are underway to provide passage pursuant to relicensing agreements.

\section{Study Design}

We evaluated how spatial and economic factors associated with restoration activities could alter predicted habitat changes and fish responses using two analyses, each consisting of two steps. We first developed a series of hypothetical watershed management scenarios. We then assessed each scenario using the evaluation framework described by Steel et al. (2008). We describe each step below.

\section{Scenarios}

Analysis 1: Total Budget and Spatial Allocation of Restoration Actions. In this analysis, we developed two sets of hypothetical watershed management scenarios intended to mimic realistic approaches to the distribution of funding for restoration projects. We followed the steps outlined in Figure 3 to develop scenarios. We ran Monte Carlo simulations to choose project locations until the budget was used up $(\mathrm{N}=20$ simulations per scenario). Each scenario-selection simulation took about 20 minutes, and variance stabilized at 20 runs so we reasoned that this sample size was sufficient for our exploratory analysis.

For both scenario sets, we evaluated the influence of total available budget (all spent in year 1) on predicted outcomes 


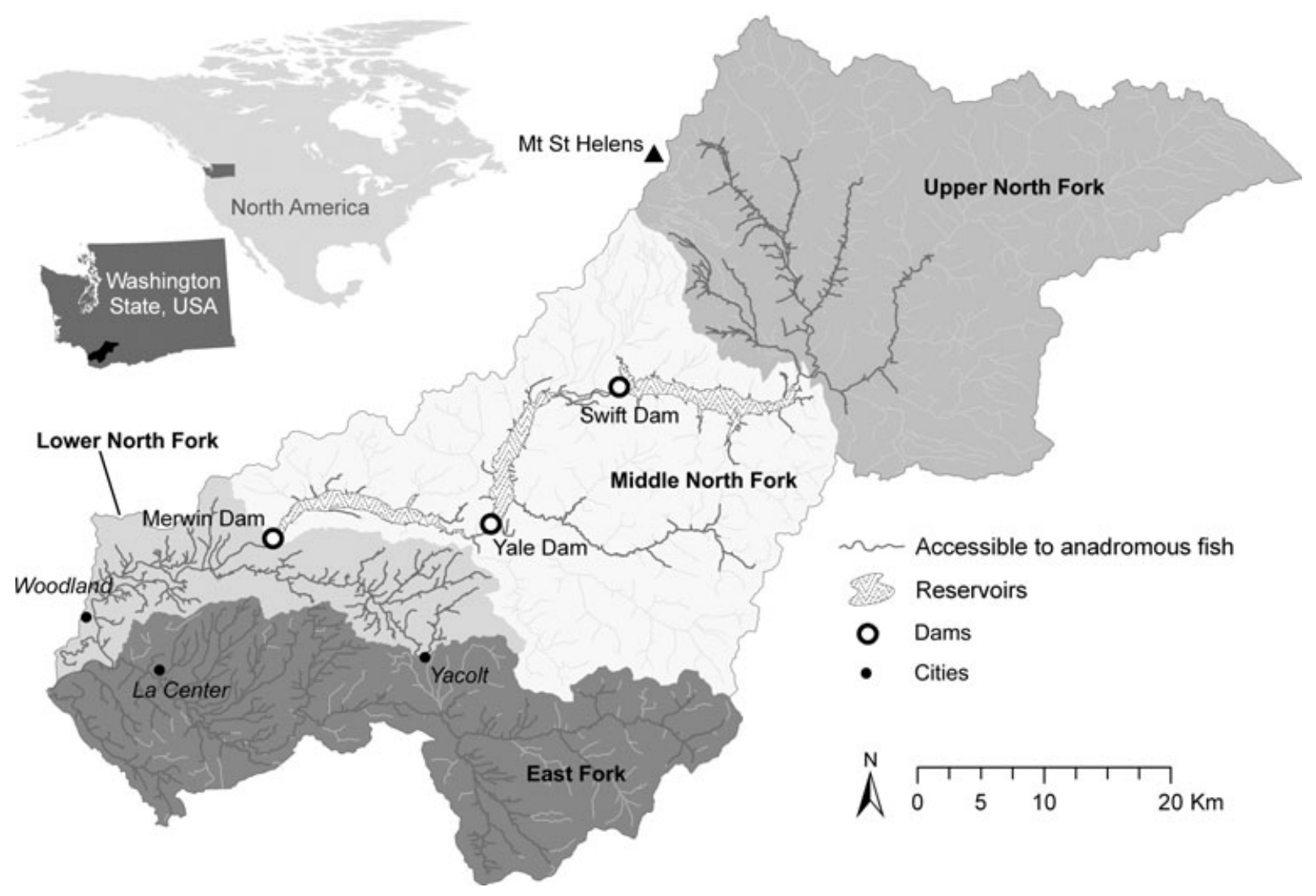

Figure 1. Map of the Lewis River Basin, showing subwatershed regions used in Analysis \#1.

50 years in the future using three budget levels: $\$ 0.75, \$ 2$, and $\$ 8$ million. We did not investigate changes that would result if projects continued to be funded for the 49 subsequent modeled years but we would expect that additional funding would yield cumulative improvements. The lower and middle budget levels fall within reasonable annual expenditure expectations (NOAA 2006). We chose the higher level to compare what might be gained at the watershed level by having a larger purse.

In the first set of scenarios (Analysis 1A), we constrained restoration actions to a particular region of the watershed (i.e., the entire budget (at each of three levels) was spent on activities located entirely within one region). We divided the watershed into four regions: East Fork $\left(606.6 \mathrm{~km}^{2} ; 1,216\right.$ stream $\mathrm{km}, 433$ of which were potentially accessible to anadromous salmonids historically), Lower North Fork $\left(260.4 \mathrm{~km}^{2}\right.$; 597 stream km, 240 fish km), Middle North Fork $\left(876.5 \mathrm{~km}^{2}\right.$; 2,031 stream km, 213 fish km), and Upper North Fork $\left(1,015.6 \mathrm{~km}^{2} ; 2,112\right.$ stream km, 196 fish $\left.\mathrm{km}\right)$ subwatersheds (Fig. 1). The East Fork and North Fork Lewis River confluence occurs very near to the mouth of the mainstem Lewis River thus East Fork subwatersheds are largely considered to be separate from North Fork subwatersheds. Streams draining to the three reservoirs were all classified as Middle North Fork, those above the top reservoir as Upper North Fork, and those below the bottom reservoir as Lower North Fork.
In the second set of scenarios (Analysis 1B), we investigated the effect of spatial distribution of project selection at each of the three budget levels. In this analysis, however, projects were not confined to any particular region in the watershed. Within each budget level, we compared two reach-level configurations: (1) random distribution of projects throughout the watershed, and (2) projects that mostly occurred on contiguous stream reaches (Fig. 4). The randomly distributed project configuration was used to mimic funding through competitive grants, whereas the spatially contiguous project configuration was intended to mimic nonrandom fund distribution such as that might happen under a top-down management scheme with a priori goals.

Analysis 2: Restoration Cost Estimates. In this analysis, we conducted a basic sensitivity analysis of project costs. We generated a series of hypothetical scenarios to evaluate how ecological outcomes would change if individual restoration actions cost $-50 \%,-25 \%,+25 \%$, or $+50 \%$ of nominal costs (Table 1). For each scenario, we allocated a total budget of $\$ 2$ million (all applied in year 1), distributed to projects entirely within one of six restoration classes: riparian protection, riparian restoration, decommissioning roads, in-stream restoration, floodplain restoration, or barrier removal. Unlike Analysis 1, we did not randomly choose project locations. 


\section{Habitat Conditions Models}

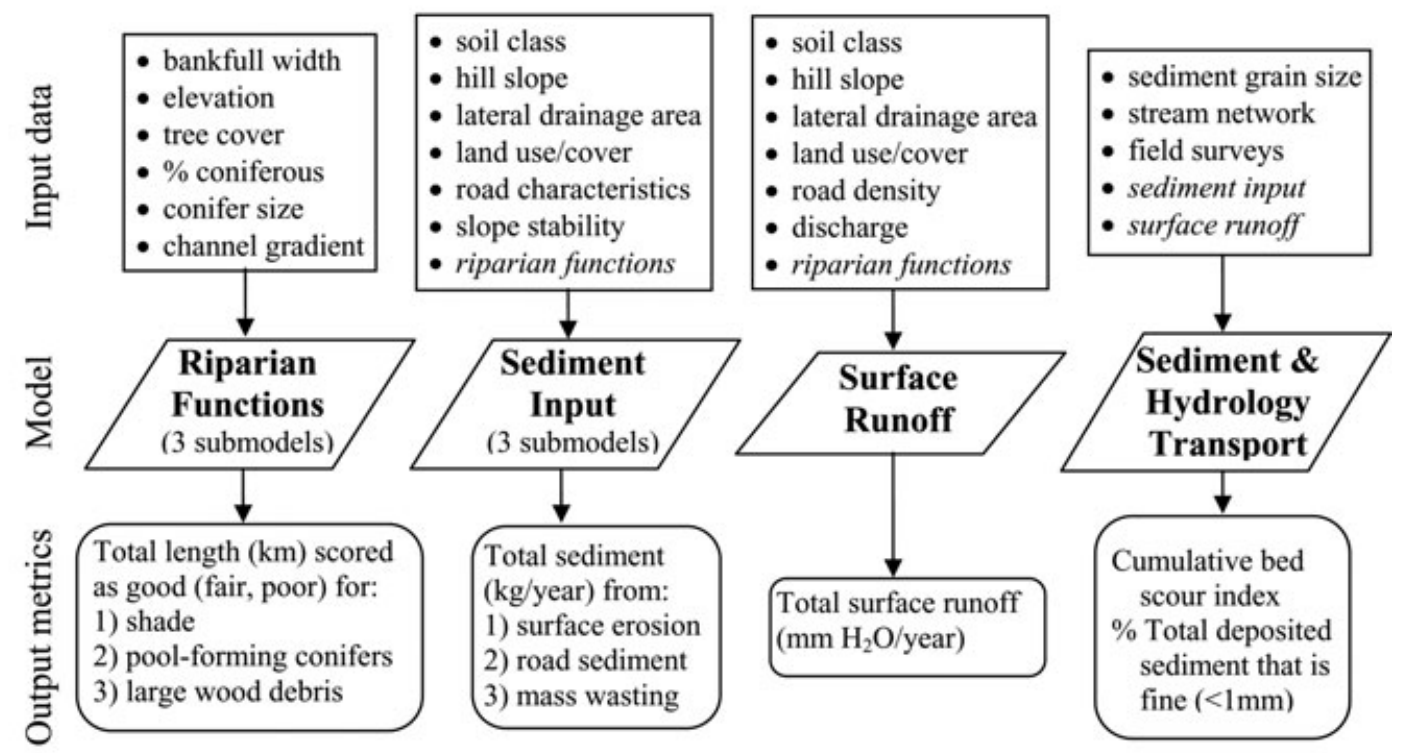

Fish Response Models

- channel gradient

- hydrol. regime

- bankfull width

- riparian functions

- bed scour index

- \% fines deposited
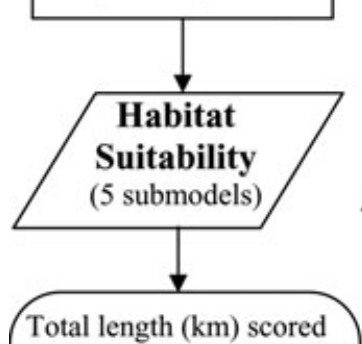

as good (adequate, fair, poor) for:

1) spring Chinook salmon

2) fall Chinook salmon

3) summer steelhead

4) winter steelhead

5) chum salmon

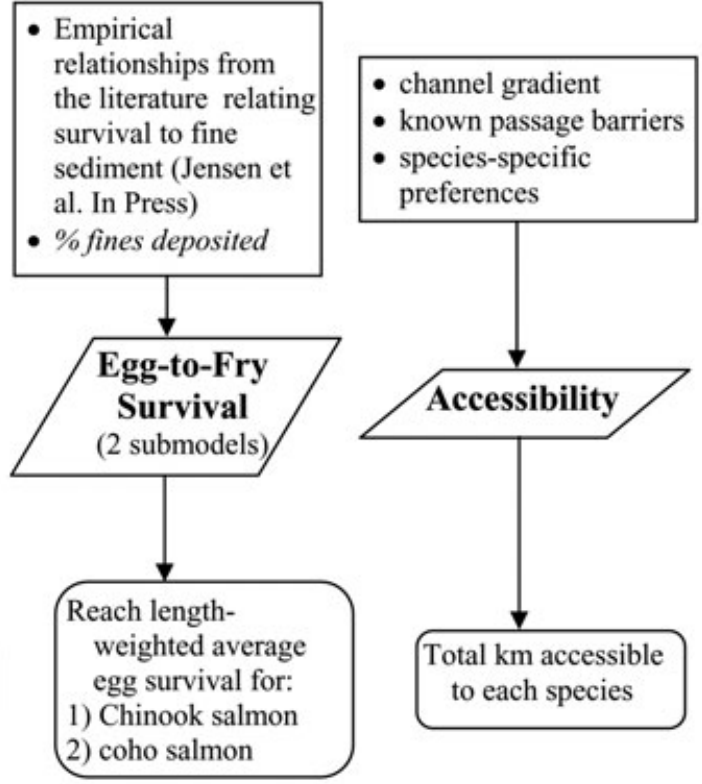

- channel gradient

- bankfull width

- riparian seral stage
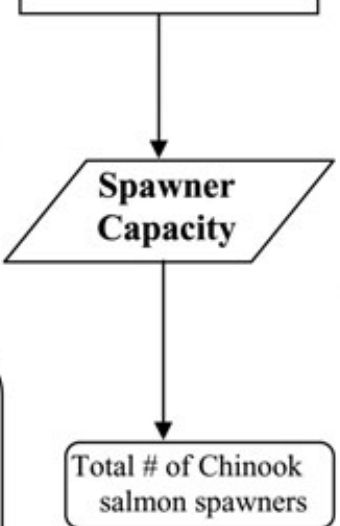

Empirical

relationships from

the literature relating

(Jensen et channel gradien

passage barriers preferences

Figure 2. Synopsis of the deterministic models (trapezoids) used to evaluate the effect of restoration actions on potential future habitat changes and fish responses. See Steel et al. (2008) for model descriptions, inputs and assumptions, and Fullerton et al. (2009) for sensitivity analysis of models. For a detailed description of how restoration actions changed the landscape, see Steel et al. 2007, appendix D. For a detailed description of each model describing how habitat conditions and fish responded to these changes in the landscape, see Steel et al. 2007, appendices E-M. For each model, inputs (bullets in boxes) are listed directly above the model name, and output metrics we used in our analysis are defined directly below (ovals). Inputs listed in italics are outputs from one of the preceding models shown here; other inputs were remotely sensed, modeled, or observed data from other sources (see Steel et al. 2008, Table 1). Results are modeled for each reach; we summarized habitat metrics over all reaches and we summarized fish metrics over reaches that were potentially accessible historically. 


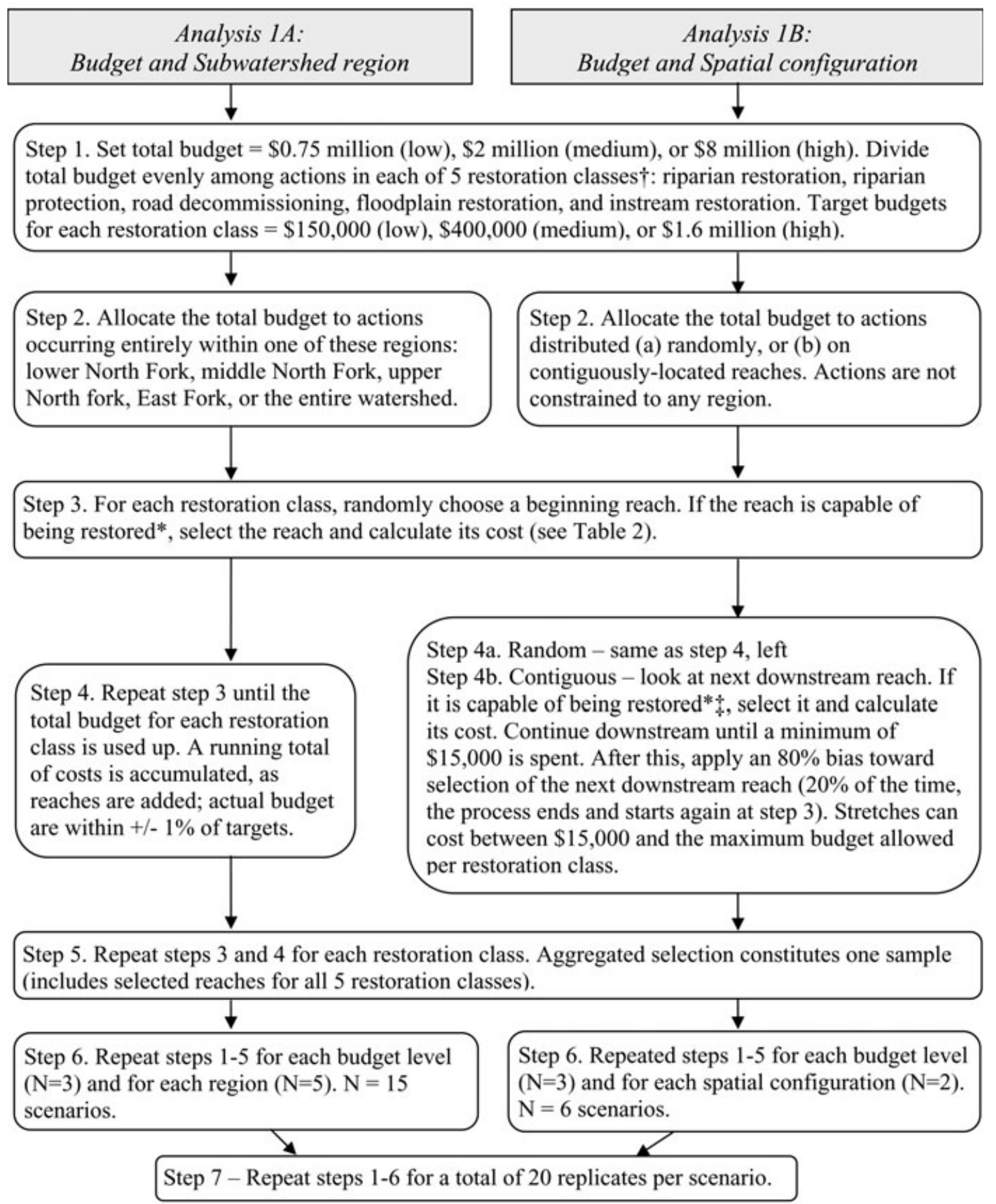

$\dagger$ We did not evaluate barrier removals.

*Riparian restoration could only occur in areas where hillslope would not preclude it $(<5 \%)$ and vegetation was capable of growing trees (i.e., not naturally bare, shrub, or grassland). Floodplain restoration could occur only on reaches that were historically located in the floodplain. Roads contributing the most sediment were given priority for decommissioning. Instream restoration could only occur in reaches where fish could conceivably spawn (i.e., bankfull width, stream gradient, and riparian conditions permitting).

$\ddagger$ Reaches $<0.1 \mathrm{~km}$ not meeting criteria qualified for inclusion.

Figure 3. Road map of steps used in Analysis \#1, applying a Monte Carlo approach to spatially locate restoration projects in each scenario $(N=20$ replicates per budget/spatial location combination). Median length of stream reaches treated per scenario was $38 \mathrm{~km}$ ( $3.5 \%$ of reaches accessible to anadromous salmonids historically) for scenarios costing \$0.75 million, $65 \mathrm{~km}(6 \%)$ for scenarios costing $\$ 2$ million, and $190 \mathrm{~km}(17.6 \%)$ for scenarios costing $\$ 8$ million. 
Analysis $1 \mathrm{~A}$

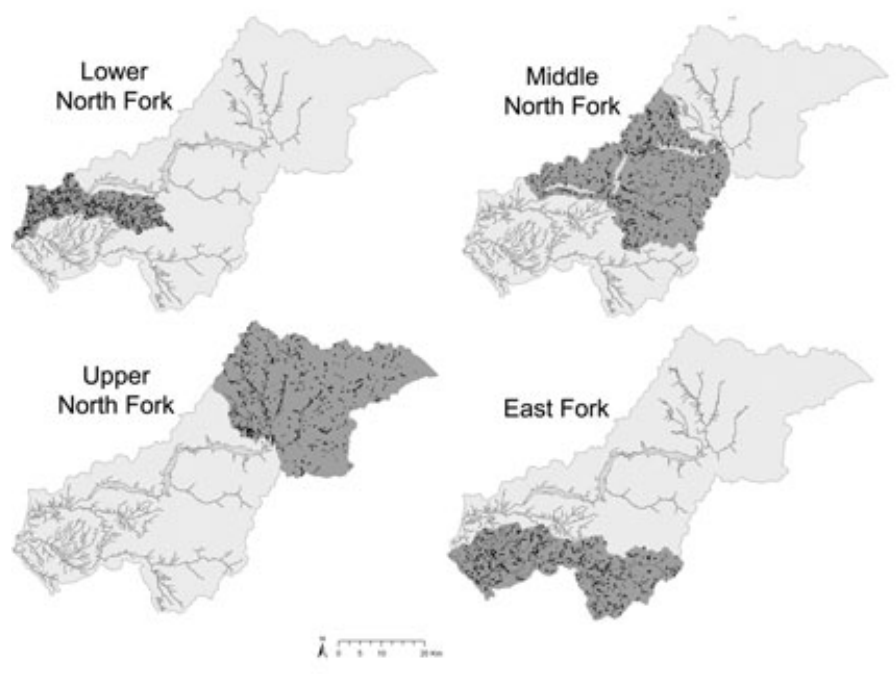

Analysis 1B

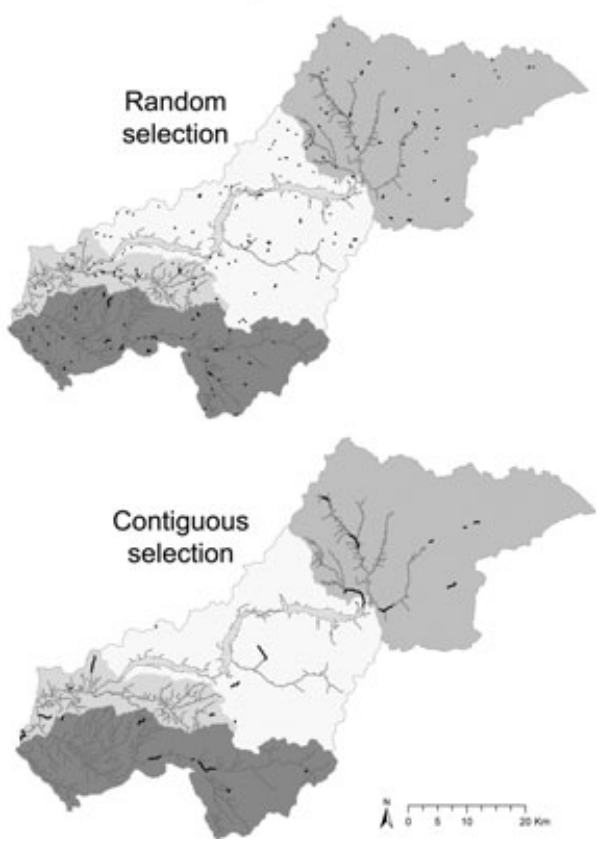

Figure 4. Example hypothetical scenarios (one of 20 replicates), illustrating the placement of restoration actions in Analysis \#1. Analysis 1A (left panel): randomly selected actions confined to each subwatershed region. Analysis 1B (right panel): actions randomly (top) or contiguously (bottom) selected throughout the watershed.

We instead applied a strategic procedure for prioritizing selection of stream reaches, roads, or barriers to be restored so that the identical set of reaches would be chosen first for each scenario (so that scenarios were directly comparable). Reaches and roads higher in the watershed were chosen first, as were barriers that opened up the most potential habitat to fish. Reaches, roads, or barriers were only chosen if they were possible to restore (see footnote in Fig. 3 for criteria). A decrease in cost associated with an action meant we were able to select more restoration projects of that class (i.e., more or longer reaches where riparian restoration occurred, or more expensive or a higher number of barriers that were removed), whereas an increase in cost required a reduction in the amount of restoration projects.

\section{Evaluation Framework}

We then evaluated each scenario with the decision-support tool customized for the Lewis River watershed by Steel et al. (2008). This tool consists of two parts: (1) translation of restoration actions in management scenarios into changes on the landscape, and (2) prediction of how stream conditions and salmon would respond to changed landscapes.

The steps used to translate specific restoration actions into changes on the landscape are described in Table 1 and in Steel et al. (2007), appendix D. Briefly; floodplain restoration increases the amount of in-stream habitat area by $40 \%$ to account for historical side channels. Barrier removal opens previously accessible habitat, and road improvement reduces the amount of sediment estimated to be contributed by roads. Riparian and in-stream restoration act directly on ecological models, improving their estimates where conditions warrant.

Each of a suite of deterministic geospatial models (Fig. 2) then evaluates the changed landscapes. Models address a variety of conditions assumed to be important for recovery of salmon populations in this basin; however, models were not available to address every risk (i.e., water quality). The Riparian Functions model is a three-part decision-tree model that predicts qualitative ratings for shade, pool-forming conifer abundance, and large woody debris recruitment provided by riparian vegetation within $60 \mathrm{~m}$ of each bank. The Sediment Supply model consists of three submodels predicting the amount of sediment supplied to streams by roads, mass wasting, and surface erosion from adjacent hillslopes. A related model, Hydrologic Runoff, predicts the amount of water contributed to streams via surface runoff. The Sediment and Water Transport model routes sediment and water contributed to each stream reach from the surrounding landscape and from an inverse-distance weighted area upstream to predict sediment transport and deposition rates. Substrate composition and bed scour are predicted from transport rates and local stream habitat survey data. The Habitat Suitability model combines species-specific spawning requirements (channel gradient, bankfull width, hydrologic regime) with anthropogenic effects (altered condition of streambed and riparian areas) to predict spawning habitat suitability. The Spawner Capacity model uses bankfull width, channel gradient, and riparian 


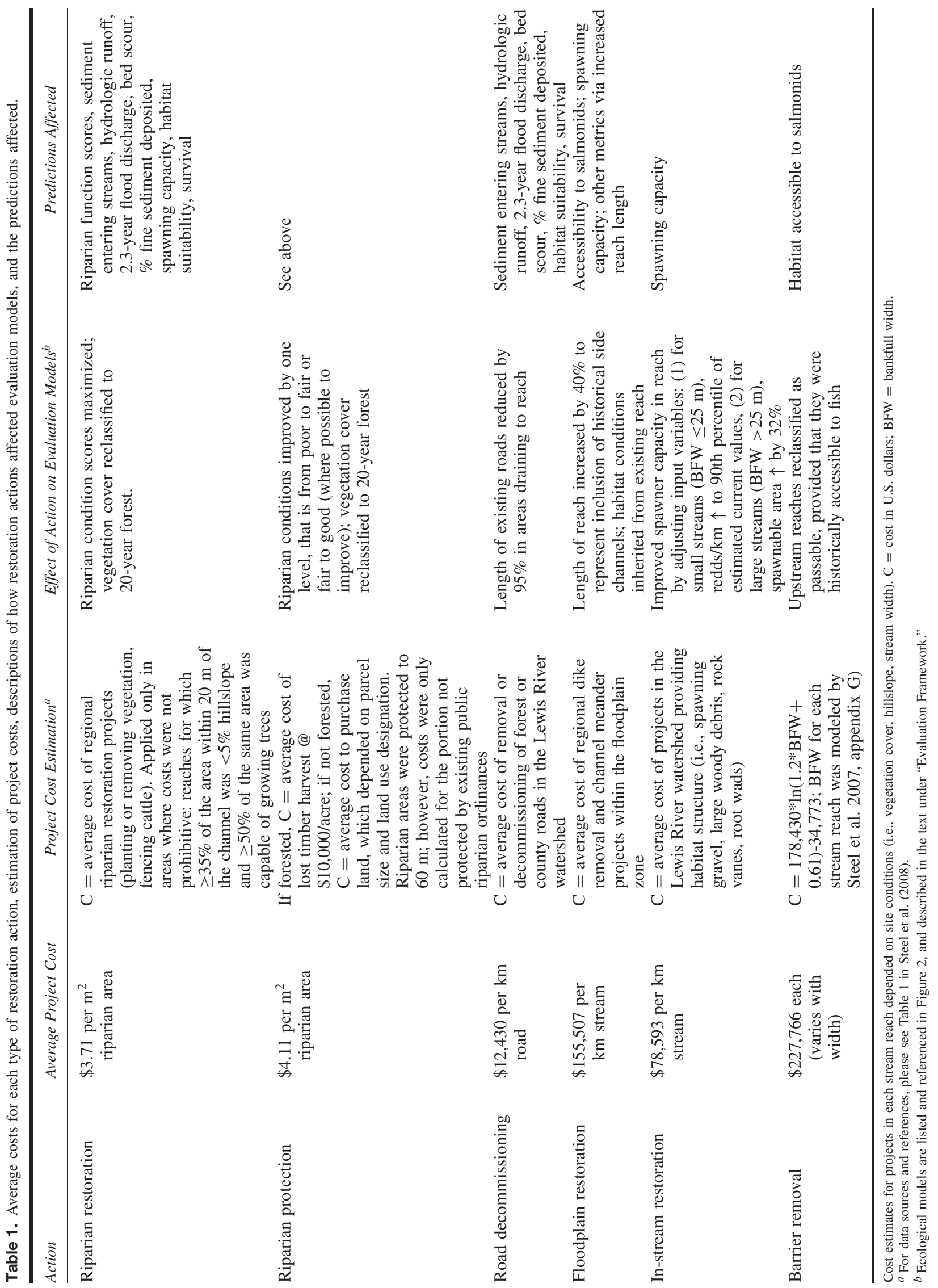


seral stage to predict capacity for Chinook salmon spawners. Egg-to-Fry Survival for Chinook and coho salmon and steelhead are predicted from empirical relationships derived from meta-analyses of published relationships between percent fine sediment in spawning gravels and survival of eggs to fry (Jensen et al. 2009). Finally, the accessibility model predicts habitat likely to be available to each species, based on gradient thresholds and known natural and anthropogenic barriers. In certain cases, outputs from some models (e.g., riparian functions, sediment, and water supply) were used as inputs to other models due to a lack of alternative sources. For a complete description of data sources and assumptions, see Steel et al. (2007, 2008).

Fullerton et al. (2009) conducted sensitivity analyses on parameters in each model to evaluate their influence on model predictions. They found most models to be robust to parameter perturbation; results were strongly sensitive to $<10 \%$ of parameters. Notably, bed scour exhibited much higher sensitivity than other predictions. There were only empirical data available to evaluate three of the metrics predicted: riparian shade, large woody debris recruitment, and fine sediment deposition. For these metrics, predictions were reasonable.

\section{Statistical Analysis}

Specific output metrics we investigated are listed in Table 1 and Figure 2. Each model predicts unique outputs for every stream reach. We summarized ecological predictions over all reaches in the watershed for habitat metrics, and over reaches that were potentially accessible prior to creation of passage barriers (e.g., dams, culverts) for fish metrics. Each metric was divided by the total scenario cost, yielding a cost-effectiveness estimate of improvement per dollar spent (hereafter, "perdollar improvements"). For Analysis 2, we calculated output metrics as improvements over existing conditions.

We determined whether there were differences in output metrics that could be explained by budget level, subwatershed region, or spatial configuration of projects using permutationbased analysis of variance (ANOVA) (PermAnova: Anderson 2001; McArdle and Anderson 2001; Anderson 2005). With this technique, customized distributions are created for each dataset from 1,000 random permutations. These distributions better fit the data than do standard distributions; thus, ANOVA is able to detect significant differences at smaller effect sizes. Pairwise comparisons were Bonferonni-adjusted.

\section{Results}

\section{Analysis 1A: Budget Level and Subwatershed Region}

As expected, predicted watershed-level habitat conditions and fish responses improved as budget level increased. For instance, at the highest budget level, total kilometers where riparian functions (shade, large woody debris) were considered to be "good" was an order of magnitude greater than that predicted at the lowest budget. However, per-dollar improvements in habitat conditions were relatively constant across the range of budgets evaluated (Table 2). Conversely, per-dollar improvements in fish responses usually increased with larger budgets, suggesting that there were increasing returns when more money was available.

For both habitat and fish results, there were numerous significant interactions between budget and region of the watershed. For example, per-dollar improvement in habitat suitability for spring Chinook was three times better at $\$ 8 \mathrm{M}$ than at $\$ 0.75 \mathrm{M}$ when restoration was constrained to the Lower North Fork (Fig. 5). Higher budget levels often exhibited lower variance than lower budgets (Fig. 5) due to larger sample sizes (i.e., more projects were selected at higher budgets).

When restoration actions were limited to specific regions of the watershed, modeled habitat conditions differed markedly among regions. For example, the total kilometers where riparian functions were considered to be "good" was highest when actions were constrained to the East Fork or Lower North Fork (Fig. 5). The amount of surface sediment and hydrologic runoff entering streams followed a similar pattern, whereas decreases in sediment from mass wasting were greatest when restoration occurred in the Middle North Fork, and decreases in sediment from roads was highest in the Upper North Fork (Table 2). Decreases in bed scour and fine sediment deposition were also greatest in the Middle and Upper North Fork regions. Many of the modeled fish responses behaved similarly, with the largest benefits seen when restoration occurred in lower regions (East Fork and Lower North Fork) (Table 2). The Lower North Fork showed the most improvement in habitat suitability for most species and for egg-to-fry survival. Improvement in fish responses was rare in the Upper and Middle North Forks.

\section{Analysis 1B: Budget Level and Spatial Configuration}

Again, watershed-level predictions of habitat conditions and fish responses improved as budget level increased. Per-dollar improvements in habitat conditions were related to total budget level about half of the time (Table 3), but it was difficult to detect a pattern among metrics. Some (e.g., riparian functions) exhibited decreasing returns as the budget increased, whereas others (i.e., surface sediment, hydrologic runoff, and mass wasting) exhibited increasing returns with increasing budget. Modeled fish responses were always related to budget level and showed an increasing return to budget size. Unlike the regional analysis, budget level seldom interacted with spatial distribution of projects.

The effect of spatial configuration of restoration actions on modeled results was often significant but differed among metrics (Table 3). Several habitat conditions exhibited greater improvements when restoration actions were distributed randomly, whereas fish responses usually performed better when restoration actions occurred primarily in larger clumps (which often tended to be along mainstem reaches). For example, riparian shade, habitat suitability for spring Chinook, and 


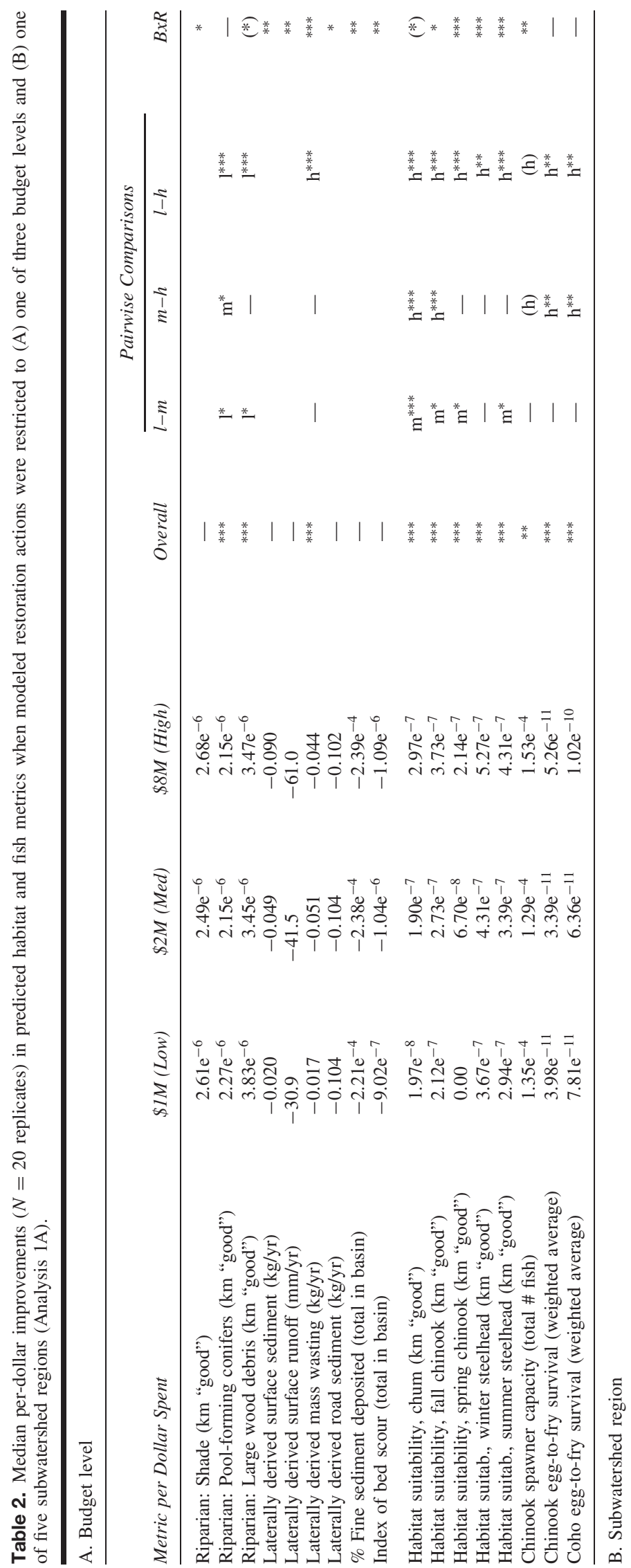

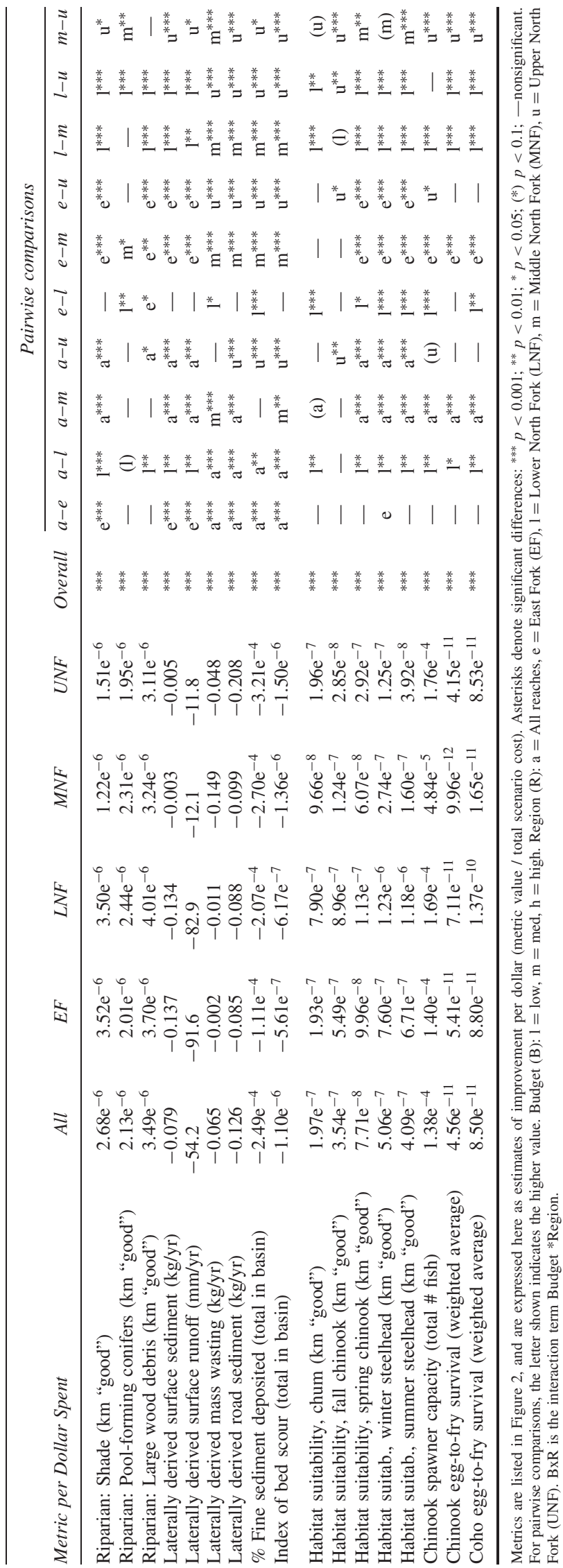




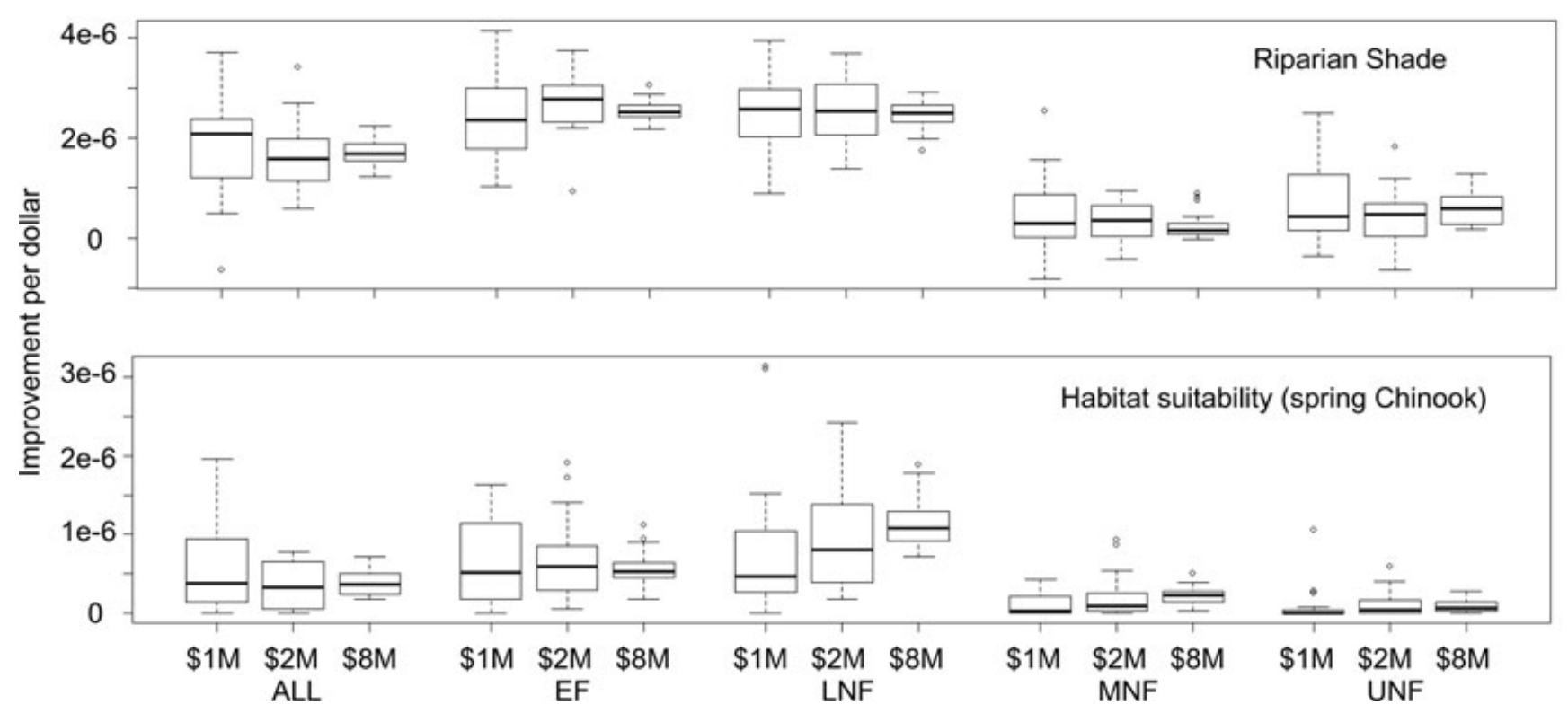

Figure 5. Example boxplots for budget level and subwatershed region results (Analysis 1A) for riparian shade (top panel) and habitat suitability for spring Chinook (bottom panel). Metrics are listed in Figure 2, and are expressed here as estimates of kilometers improved per dollar (metric value/total scenario cost). Abbreviations: $\mathrm{M}=$ million; $\mathrm{ALL}=$ all reaches in the watershed; $\mathrm{LNF}=$ lower North Fork Lewis River; MNF $=$ Middle North Fork; $\mathrm{UNF}=$ Upper North Fork; EF $=$ East Fork. Boxplot lines are medians, box edges are 75th percentiles, and whiskers are 95th percentiles.

Chinook egg-to-fry survival all showed greater improvements when restoration actions occurred on contiguous reaches (Fig. 6). Conversely, sediment input from roads and the percent of fine sediment deposited in streams were reduced to a greater extent (i.e., improved more) when actions were distributed randomly (Fig. 6).

\section{Analysis 2: Restoration Cost Estimates}

For most restoration classes, a one-time initial budget of \$2 million was only capable of fixing a small proportion of what was possible to restore in the watershed (relative to presumed undisturbed natural conditions) (Fig. 7). We recognize that this is a simplification and that in reality projects will be funded on a continuing basis. When project costs were $50 \%$ lower than nominal estimates (Table 1), road decommissioning and barrier removal improved almost a third of what was possible to fix, but only a small fraction of potential improvement was achieved for other response metrics. Generally, more improvement in habitat conditions and fish responses occurred when restoration project costs were lower. At the highest project cost $(50 \%$ over nominal estimates), predicted improvements were usually less than half of what was possible when project cost was lowest $(50 \%$ less than nominal costs). However, restoration actions that increased access to habitat did not follow this pattern for some metrics. The most improvement in habitat suitability and spawner capacity occurred when floodplain restoration costs were $25 \%$ less, and when barrier removal costs were set to nominal estimates.

Predicted shade from riparian trees (Fig. 7a) was approximately equally sensitive to changes in riparian protection, riparian restoration, and floodplain restoration costs. Sediment contributed from roads (Fig. 7b) was most sensitive to cost of road decommissioning, but was also sensitive to cost of riparian conservation actions. Habitat suitability (Fig. 7c) was sensitive to a variety of types of restoration, and there was a substantial drop in improvement between costs of $-50 \%$ and $-25 \%$ for riparian and road restoration. Spawner capacity (Fig. 7d) was most sensitive to cost of in-stream restoration, but was also affected by floodplain restoration and barrier removal costs. Egg-to-fry survival (Fig. 7e) improved the most when road decommissioning was the least expensive, but was also affected by changing costs of floodplain restoration and barrier removal. Finally, the amount of accessible habitat (Fig. 7f) was more sensitive to cost of floodplain restoration than to cost of barrier removal.

\section{Discussion}

Ideally, restoration projects might be prioritized in terms of ecosystem valuation (Loomis et al. 2000; Collins et al. 2005), where benefits are expressed in dollars. However, this is extremely difficult to implement in practice (Plummer 2005). Management decisions can instead be made using ecological improvement metrics such as reduced in-stream sediment or increased useable habitat as proxies for economic benefits (Gowan et al. 2006). We used this approach, extending a cost-effectiveness analysis (a.k.a. "biggest bang for the buck"; e.g., Wernstedt \& Paulsen 1995; Newbold et al. 2005) by determining the sensitivity of ecological metrics to a variety of restoration strategies. Sensitivity analyses (e.g., Merrifield 1997; Saltelli et al. 2000) are essential because they examine 
Table 3. Median per-dollar improvements ( $N=20$ replicates) in predicted habitat and fish metrics when modeled restoration actions were restricted to (A) one of three budget levels and (B) projects were distributed either randomly or on contiguous reaches (Analysis 1B).

A. Budget level

\begin{tabular}{|c|c|c|c|c|c|c|c|c|}
\hline Metric per Dollar Spent & $\$ 1 M($ Low $)$ & $\$ 2 M(M e d)$ & $\$ 8 M($ High $)$ & Overall & \multicolumn{3}{|c|}{ Pairwise Comparisons } & $B x S$ \\
\hline Riparian: Shade (km “good”) & $3.2 \mathrm{e}^{-6}$ & $3.3 \mathrm{e}^{-6}$ & $3.0 \mathrm{e}^{-6}$ & $* *$ & - & $\mathrm{m}^{*}$ & - & - \\
\hline Riparian: Pool-forming conifers (km "good") & $2.4 \mathrm{e}^{-6}$ & $2.4 \mathrm{e}^{-6}$ & $2.3 \mathrm{e}^{-6}$ & $* * *$ & - & - & $1^{* * *}$ & - \\
\hline Riparian: Large wood debris (km "good") & $4.0 \mathrm{e}^{-6}$ & $4.2 \mathrm{e}^{-6}$ & $3.8 \mathrm{e}^{-6}$ & - & & & & - \\
\hline Laterally derived surface sediment (kg/yr) & -0.036 & -0.080 & -0.083 & $* * *$ & - & - & $\mathrm{h}^{* * *}$ & $*$ \\
\hline Laterally derived road sediment ( $\mathrm{kg} / \mathrm{yr})$ & -0.120 & -0.111 & -0.115 & - & & & & \\
\hline$\%$ Fine sediment deposited (total in basin) & $-1.4 \mathrm{e}^{-4}$ & $-1.4 \mathrm{e}^{-4}$ & $-1.7 \mathrm{e}^{-4}$ & - & & & & - \\
\hline Index of bed scour (total in basin) & $-7.8 \mathrm{e}^{-7}$ & $-9.5 \mathrm{e}^{-7}$ & $-8.9 \mathrm{e}^{-7}$ & - & & & & - \\
\hline Habitat suitability, chum (km “good") & $7.9 \mathrm{e}^{-9}$ & $3.6 \mathrm{e}^{-7}$ & $4.4 \mathrm{e}^{-7}$ & $* * *$ & $\mathrm{~m}^{*}$ & $\mathrm{~h}^{*}$ & $\mathrm{~h}^{* * *}$ & - \\
\hline Habitat suitability, fall chinook (km "good") & $6.3 \mathrm{e}^{-8}$ & $3.4 \mathrm{e}^{-7}$ & $5.9 \mathrm{e}^{-7}$ & $* * *$ & $\mathrm{~m}^{*}$ & $\mathrm{~h}^{*}$ & $\mathrm{~h}^{* * *}$ & - \\
\hline Chinook egg-to-fry survival (weighted average) & $4.4 \mathrm{e}^{-11}$ & $4.9 \mathrm{e}^{-11}$ & $6.1 \mathrm{e}^{-11}$ & $* * *$ & - & - & $\mathrm{h}^{* * *}$ & $*$ \\
\hline Coho egg-to-fry survival (weighted average) & $8.8 \mathrm{e}^{-11}$ & $1.0 \mathrm{e}^{-10}$ & $1.2 \mathrm{e}^{-10}$ & $* * *$ & - & - & $\mathrm{h}^{* *}$ & - \\
\hline
\end{tabular}

B. Spatial configuration

\begin{tabular}{|c|c|c|c|c|}
\hline Metric per Dollar Spent & Random & Contiguous & Overall & $r-c$ \\
\hline Riparian: Shade (km “good”) & $2.7 \mathrm{e}^{-6}$ & $3.7 \mathrm{e}^{-6}$ & $* * *$ & $\mathrm{c}$ \\
\hline Riparian: Pool-forming conifers (km "good") & $2.1 \mathrm{e}^{-6}$ & $2.6 \mathrm{e}^{-6}$ & $* *$ & $\mathrm{c}$ \\
\hline Riparian: Large wood debris (km "good") & $3.5 \mathrm{e}^{-6}$ & $4.6 \mathrm{e}^{-6}$ & $* * *$ & $\mathrm{c}$ \\
\hline Laterally derived surface sediment (kg/yr) & -0.079 & -0.069 & - & - \\
\hline Laterally derived surface runoff $(\mathrm{mm} / \mathrm{yr})$ & -54.2 & -60.3 & - & - \\
\hline Laterally derived mass wasting $(\mathrm{kg} / \mathrm{yr})$ & -0.065 & -0.076 & $* *$ & $\mathrm{c}$ \\
\hline Laterally derived road sediment $(\mathrm{kg} / \mathrm{yr})$ & -0.126 & -0.093 & $* * *$ & $\mathrm{r}$ \\
\hline$\%$ Fine sediment deposited (total in basin) & $-2.5 \mathrm{e}^{-4}$ & $-7.1 \mathrm{e}^{-5}$ & $* * *$ & $\mathrm{r}$ \\
\hline Index of bed scour (total in basin) & $-1.1 \mathrm{e}^{-6}$ & $-5.4 \mathrm{e}^{-7}$ & $* * *$ & r \\
\hline Habitat suitability, chum (km "good") & $2.0 \mathrm{e}^{-7}$ & $4.8 \mathrm{e}^{-7}$ & - & - \\
\hline Habitat suitability, fall chinook (km "good") & $7.7 \mathrm{e}^{-8}$ & $6.9 \mathrm{e}^{-7}$ & $* *$ & $\mathrm{c}$ \\
\hline Habitat suitability, spring chinook (km "good") & $3.5 \mathrm{e}^{-7}$ & $4.6 \mathrm{e}^{-7}$ & $* * *$ & $\mathrm{c}$ \\
\hline Habitat suitability, winter steelhead (km "good") & $5.1 \mathrm{e}^{-7}$ & $1.1 \mathrm{e}^{-6}$ & $* * *$ & $\mathrm{c}$ \\
\hline Habitat suitability, summer steelhead (km "good") & $4.1 \mathrm{e}^{-7}$ & $9.0 \mathrm{e}^{-7}$ & $* * *$ & $\mathrm{c}$ \\
\hline Chinook spawner capacity (total \# fish) & $1.4 \mathrm{e}^{-4}$ & $1.6 \mathrm{e}^{-4}$ & - & - \\
\hline Chinook egg-to-fry survival (weighted average) & $4.6 \mathrm{e}^{-11}$ & $7.7 \mathrm{e}^{-11}$ & $* * *$ & $\mathrm{c}$ \\
\hline Coho egg-to-fry survival (weighted average) & $8.5 \mathrm{e}^{-11}$ & $1.4 \mathrm{e}^{-10}$ & $* * *$ & $\mathrm{c}$ \\
\hline
\end{tabular}

Metrics are listed in Figure 2, and are expressed here as estimates of improvement per dollar (metric value/total scenario cost). Asterisks denote significant differences: *** $p<0.001$; ** $p<0.01$; ${ }^{*} p<0.05 ;(*) p<0.1 ;-$ nonsignificant. For pairwise comparisons, the letter shown indicates the higher value. $1=$ low, $\mathrm{m}=\mathrm{med}$, $\mathrm{h}=$ high; $\mathrm{c}=$ contiguous, $\mathrm{r}=$ random. $\mathrm{BxS}$ is the interaction term Budget $*$ Spatial configuration.

some of the multiple sources of uncertainty (Lek 2007) that managers face when trying to make decisions about how and where to spend limited habitat restoration funds. The factors comprising our simulated restoration scenarios (budget size, project costs, and spatial considerations) come from common issues that managers are faced with and those the literature suggests are relevant to ecological outcomes. Our simulation exercises showed that these real-life constraints can affect predicted benefits from restoration. Our work contributes toward greater understanding of watershed-scale effects of project distribution as well as how regional characteristics influence potential improvement. Specifically, these analyses contribute to freshwater restoration planning by answering the following questions. 


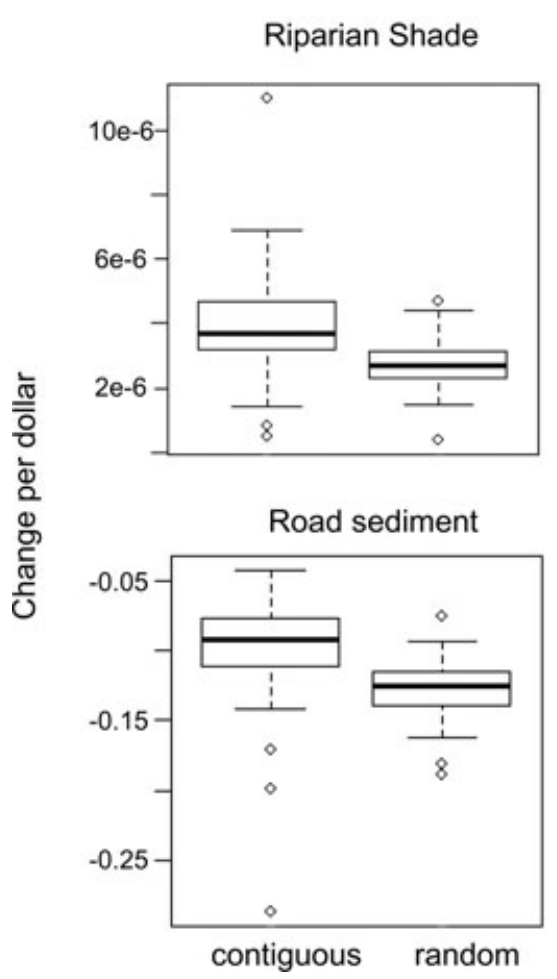

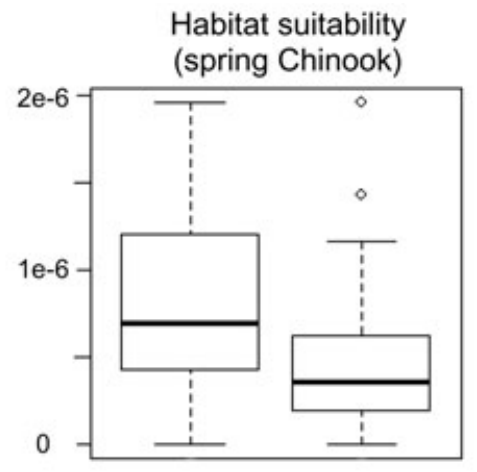

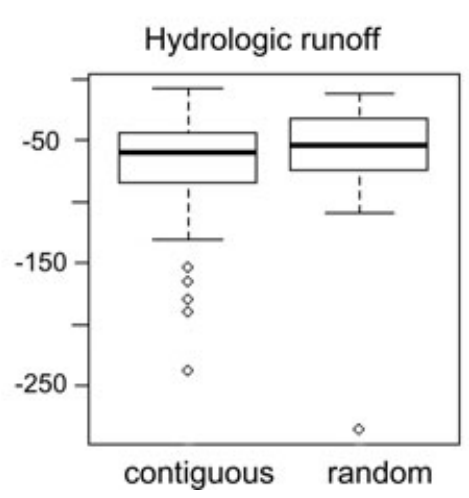

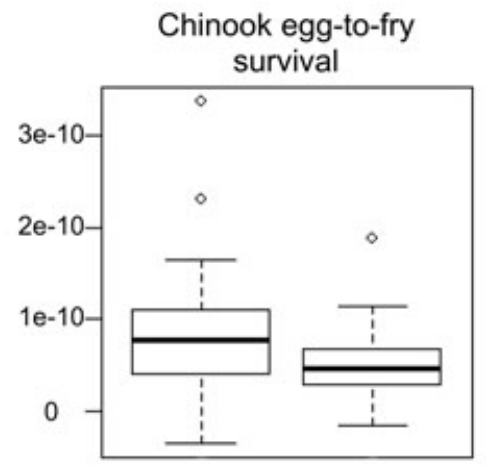

$\%$ Fine sediment deposited

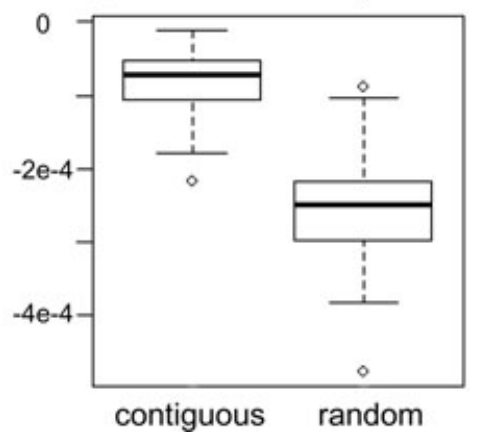

Figure 6. Example boxplots for spatial configuration results (Analysis 1B). Budget levels were pooled in this figure to isolate spatial effects. Metrics are listed in Figure 2, and are expressed here as estimates of improvement per dollar (metric value/total scenario cost). Note that in the top row, positive values indicate improvement, whereas in the bottom row, negative values indicate improvement. Abbreviations: $\mathrm{M}=$ million; ALL = all reaches in the watershed; LNF = lower North Fork Lewis River; MNF = Middle North Fork; UNF = Upper North Fork; EF = East Fork. Boxplot lines are medians, box edges are 75 th percentiles, and whiskers are 95 th percentiles.

\section{How do Local Conditions Constrain What is Possible to Restore?}

We found unique opportunities and limitations for each region of the watershed we examined due to local landscape and stream characteristics. The upper watershed responded well to road restoration but improvements were not largely visible for fish responses in that region. Conversely, there was little response to road restoration in the lower watershed, but very large responses in these regions to improvements in riparian conditions. The lower watershed, not surprisingly, showed the largest improvements for fish responses because effects of restoration in the upper basin trickle downstream, in addition to direct effects of local restoration in lower reaches.

Budget level interacted with region of the watershed, again suggesting that certain regions were limited in what could be accomplished. For example, in the Middle North Fork Lewis River, riparian large woody debris recruitment was already in fairly good condition, and only a small or moderate amount of restoration was needed. Additional funding at the highest budget level therefore yielded diminishing returns because there was not much habitat left to restore. Identifying subwatershed-specific goals (i.e., prioritizing which metrics are important to improve) and recognizing which restoration actions are likely to yield the largest benefit in a particular subwatershed will promote efficient use of project funds.

\section{How do Predicted Benefits Respond to Spatial Distribution of Restoration Projects?}

We saw more per-dollar improvement in predicted fish responses when restoration projects occurred in close proximity (i.e., on contiguous stretches of stream) than when restoration was randomly distributed. This could be because stretches that were long enough to qualify for contiguous restoration projects often turned out to be larger tributaries and mainstems (i.e., headwater reaches were too short to qualify). These often coincided with reaches occupied by fish (recall that fish responses were summarized only over fish-accessible reaches, which often omitted headwaters). Riparian conditions, which were summarized over all reaches, also benefited from restoration along longer stretches of stream. Conversely, sediment from roads and fine sediment deposited in streams were often improved (i.e., were reduced to a greater extent) when restoration occurred at random locations. These metrics were most directly affected by road decommissioning, and the largest reduction in sediment coming from roads occurred in headwater tributaries in the upper watershed. There was no clear pattern for the effect of spatial distribution of projects on other sources of sediment.

Based on our results, managers might choose to focus riparian restoration or restoration targeted to improve in-stream fish habitat on longer stretches of stream. However, for road 


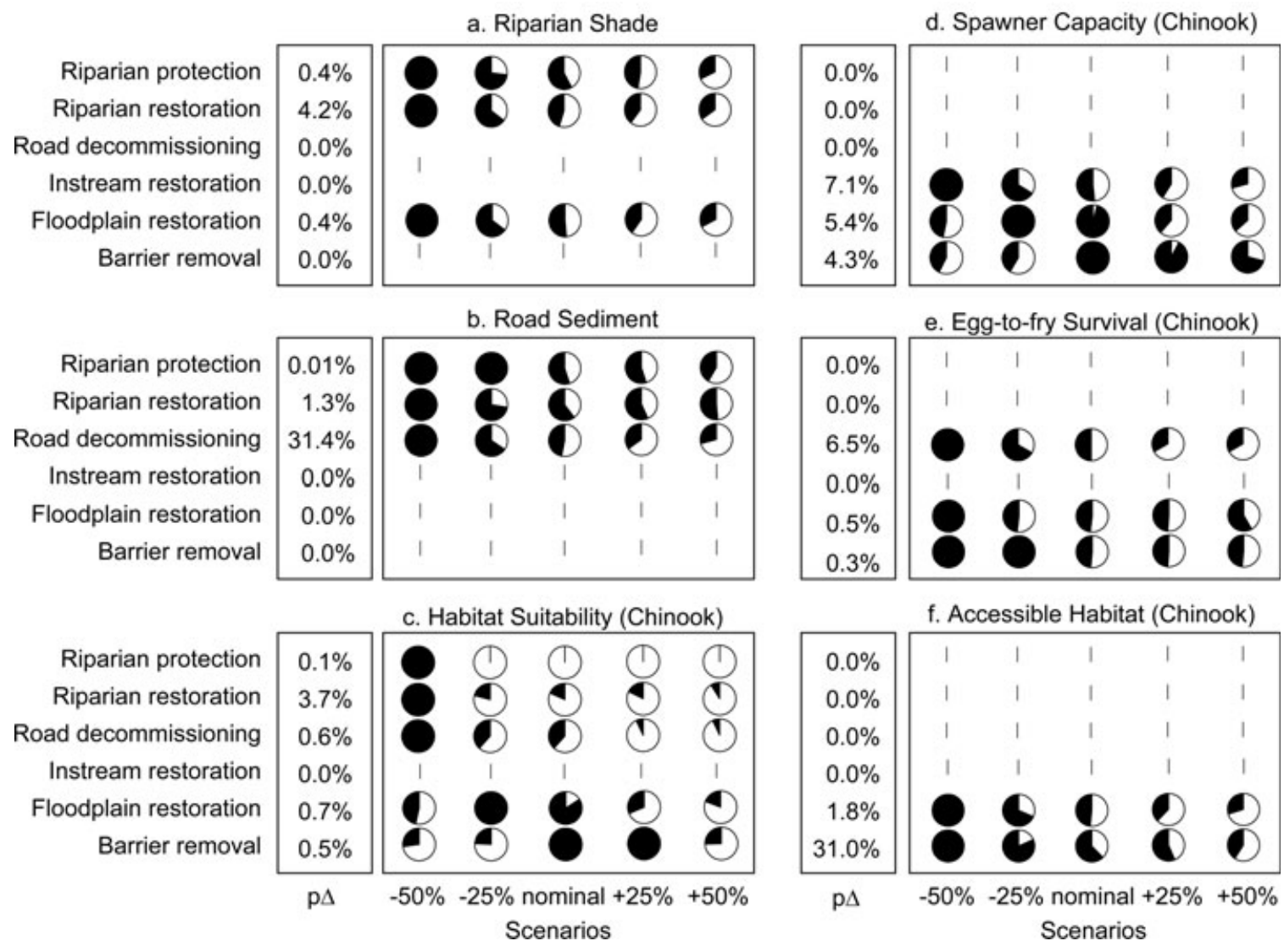

Figure 7. Changes predicted in six evaluation metrics (panels a-f) when costs of individual restoration actions (listed on the left side of each panel) were increased or decreased by $25 \%$ or $50 \%$ over nominal costs (nominal costs are listed in Table 1). Values to the left of each panel show the potential change $(\mathrm{p} \Delta)$, that is, the proportion of estimated historical conditions that was achieved by the best scenario. Pie charts show what was achieved by each scenario relative to $\mathrm{p} \Delta$ for a given metric. Therefore, the best scenario for each metric is represented as a completely filled pie-chart (usually the scenario where actions were 50\% less expensive). Lines indicate that there was no response. For example, panel c describes how sensitive habitat suitability for spring Chinook was to each restoration action. The most improvement occurred when riparian and road restoration were 50\% less expensive, when floodplain restoration was $25 \%$ less expensive, and at nominal barrier removal costs.

restoration projects, our results suggest that larger benefits are possible by locating projects opportunistically, wherever landowners are willing and conditions warrant, prioritizing roads that contribute the most sediment. In practice, road restoration could exhibit an economy of scale, because the initial costs (e.g., bringing in an excavator to decommission a stretch of road) would likely be lower for a few contiguous stretches of road than for a larger number of isolated locations.

\section{Does a Bigger Budget Yield More Benefit?}

As expected, the ability to implement more projects yielded larger basin-wide improvements overall, although most perdollar habitat metrics exhibited constant or decreasing returns to budget size. However, per-dollar fish metrics often exhibited increasing returns to budget size. In other words, each subsequent dollar added to the budget had a larger impact on fish metrics than the previous dollar. One potential cause of this unexpected result is that when restoration projects were chosen randomly (to represent an opportunistic funding scheme), projects were selected inefficiently, and a larger budget captured more of the efficient projects by default (i.e., by throwing a larger net). If funding decisions are made rationally, efficient projects would most likely be chosen first, and there would be a net decrease in returns at higher budget levels. Alternatively, at higher budgets, multiple types of restoration actions were more likely to occur on coincident sets of reaches, and we may have been simply seeing the cumulative benefit of multiple restoration actions, which are reflected by fish metrics (whereas habitat metrics usually reflect only one or two action types). Add to this the potential advantage received by fishaccessible reaches (those found low in the watershed) because they are recipients of both restoration targeted locally as well as indirectly by restoration in the upper watershed. This result needs to be further explored (i.e., using many more simulations) to determine whether the effect is real, and which is more likely to be a causal mechanism. We echo Jansson et al. (2007) that future research is needed to investigate the potential cumulative effects of multiple projects, and the best location of projects to maximize outcomes. 


\section{How do Costs of Restoration Projects Impact Predicted Outcomes?}

A realistic concern of managers is that restoration projects may become more or less expensive depending on local conditions, labor rates, gas prices, and other factors such as financial incentives to landowners. Our analysis did not attempt to truly minimize costs for a given level of a metric within a scenario due to modeling constraints, nor did we investigate potential interactions of costs among different types of restoration. However, our basic sensitivity analysis was able to identify some general patterns that will improve decision-making capabilities. First, predictions usually followed an expected trend: watershed-level improvements, in-stream habitat conditions and fish responses decreased with increasing restoration project costs because fewer projects could be afforded. However, each metric (e.g., predicted habitat condition or fish response) had a unique response to varying costs of the different types of restoration actions. Therefore, managers should think carefully about which responses they are trying to generate with a particular set of actions. Some metrics were more sensitive to particular types of restoration. If these metrics are important management goals, it is critical to know how more funds should be allocated to fixing problems that affect them. A second interesting result we found was that restoration which opened new habitat (e.g., floodplain restoration and barrier removal) affected several metrics (e.g., habitat suitability and spawner capacity) in ways that did not follow the expected trend of more improvement when costs were reduced. For these metrics, project location and initial conditions were likely more important than the total amount of restoration. Simply opening more new habitat did not necessarily mean that the new habitat was going to be in good condition.

Estimating accurate project costs can impede successful restoration planning because spatial variability in project costs can be large (Naidoo et al. 2006). Ignoring variability, especially when those costs come from the high development potential of a piece of land, may provide inferior ecological improvements (Newburn et al. 2005). Simulation analyses such as ours can improve restoration planning by providing a range of expected outcomes under a variety of economic conditions (Merrifield 1997).

\section{Conclusions}

Given the amount of resources that are being allocated to habitat restoration (Bernhardt et al. 2005), it is imperative that managers consider the impact that their choices may have on future conditions. Sensitivity analyses (Merrifield 1997; Lek 2007) such as the ones we conducted can be used to identify patterns and linkages that will inform management decisions. By considering uncertainties, tradeoffs between competing candidate strategies should become more transparent. Simulation modeling is a useful tool for understanding potential long-term impacts of habitat restoration that would have been difficult to evaluate empirically over large spatial scales (DeAngelis et al. 1998; Santelmann et al. 2004). Even if we could have conducted experiments over large enough spatial extents, predictions could not have been evaluated without decades or centuries of monitoring. Our approach lends itself well to restoration planning in other regions and for other species for which spatial and temporal horizons are very large. Our findings suggest new questions, both in aquatic systems and in other ecosystems. For example, we found that the proximity of restoration projects may contribute to restoration success for Pacific salmonids in rivers. How do spatial dependencies of restoration efforts differ in other landscapes? We found that there are regionally appropriate restoration actions; this could influence conservation reserve design and large-scale management plans. And finally, economic factors showed many nonlinearities, such as a cumulative benefits to salmonid populations with increases in restoration budgets. These results echo others (e.g., Waetzold et al. 2006) in arguing for the integration of economic and ecological analyses in any restoration planning effort.

\section{Implications for Practice}

- Scenario-planning simulations can help managers consider future effects of decisions before long-term monitoring results are available to ensure that restoration funds are spent on the most cost-efficient and ecologically effective projects.

- Because local site conditions drive the types and amounts of restoration that are most likely to be effective over larger spatial extents, managers should carefully consider system-wide goals when prioritizing actions. Our results suggest that certain types of restoration projects would yield greater benefits when conducted in close proximity (i.e., along contiguous reaches of river), but that others would ideally be placed opportunistically.

- Benefits from restoration actions we modeled were related to costs (i.e., increases in budgets resulted in proportionate increases in benefits). In some cases, there may be economies of scale (i.e., increasing benefits per dollar spent) when larger restoration budgets are available. Further assessment is needed to determine whether modeled economies of scale are realistic.

\section{Acknowledgments}

We thank J. Davies, M. Plummer, and P. Roni for comments on earlier versions of this article. Funding was provided by NOAA Fisheries Service, and by an internal grant from the Northwest Fisheries Science Center to AHF.

\section{LITERATURE CITED}

Anderson, M. J. 2001. A new method for non-parametric multivariate analysis of variance. Australian Ecology 26:32-46.

Anderson, M. J. 2005. PERMANOVA: a FORTRAN computer program for permutational multivariate analysis of variance. Department of Statistics, University of Auckland, New Zealand. 
Ando, A., J. Camm, S. Polasky, and A. Solow. 1998. Species distributions, land values and efficient conservation. Science 279:2126-2128.

Baker, J. P., D. W. Hulse, S. V. Gregory, D. White, J. Van Sickle, P. A. Berger, D. Dole, and N. H. Schumaker. 2004. Alternative futures for the Willamette River Basin, Oregon. Ecological Applications 14:313-324.

Battin, J., M. W. Wiley, M. H. Ruckelshaus, R. N. Palmer, E. Korb, K. K. Bartz, and H. Imaki. 2007. Projected impacts of climate change on salmon habitat restoration. Proceedings of the National Academy of Science 104:6720-6725

Bernhardt, E. S., M. A. Palmer, J. D. Allan, G. Alexander, K. Barnas, S. Brooks, et al. 2005. Synthesizing U.S. river restoration efforts. Science 308:636-637.

Chan, S. K. F., I. J. Cheng, T. Zhou, H. J. Wang, H. X. Gu, and X. J. Song. 2007. A comprehensive overview of the population and conservation status of sea turtles in China. Chelonian Conservation and Biology 6:185-198.

Collins, A., R. Rosenberger, and J. Fletcher. 2005. The economic value of stream restoration. Water Resources Research 41:W02017, doi:10.1029/ 2004WR003353.

Crooks, K. R. and M. Sanjayan. 2006. Connectivity conservation. Cambridge University Press, Massachusetts, p.712.

Cumming, G. S. 2007. Global biodiversity scenarios and landscape ecology. Landscape Ecology 22:671-685.

DeAngelis, D. L., L. J. Gross, M. A. Huston, W. F. Wolff, D. M. Fleming, E. J. Comiskey, and S. M. Sylvester. 1998. Landscape modeling for everglades ecosystem restoration. Ecosystems 1:64-75.

Dobson, A.P., J. P. Rodriguez, W. M. Roberts, and D. S. Wilcove. 1997. Geographic distribution of endangered species in the United States. Science 275:550-553.

Ferraro, J. 2003. Assigning priority to environmental policy interventions in a heterogeneous world. Journal of Policy Analysis and Management 22:27-43

Fullerton, A. H., D. Jensen, E. A. Steel, D. Miller, and P. McElhany. 2009. How certain are salmon recovery forecasts? A watershed-scale sensitivity analysis. Environmental Modeling and Assessment. doi: 10.1007/s10666008-9185-z (available from http://www.springerlink.com/content/q87 $\operatorname{tg} 54301648614 / ? \mathrm{p}=\mathrm{c} 056469 \mathrm{fc} 07 \mathrm{a} 44 \mathrm{c} 985 \mathrm{cal}$ da86f9f $1514 \& \mathrm{pi}=3$ [accessed 11 March 2009)

Goulson, D., G. C. Lye, and B. Darvill. 2008. Decline and conservation of bumble bees. Annual Review of Entomology 53:191-208.

Gowan, C., K. Stephenson, and L. Shabman. 2006. The role of ecosystem valuation in environmental decision making: hydropower relicensing and dam removal on the Elwha River. Ecological Economics 56:508-523.

Haight, R. G., B. Cypher, P. A. Kelly, S. Phillips, H. P. Possingham, K. Ralls, A. M. Starfield, P .J. White, and D. Williams. 2002. Optimizing habitat protection using demographic models of population viability. Conservation Biology 16:1386-1397.

Haines, A. M., M. E. Tewes, L. L. Laack, J. S. Horne, and J. H. Young. 2006. A habitat-based population viability analysis for ocelots (Leopardus pardalis) in the United States. Biological Conservation 132:424-436.

Jansson, R., C. Nilsson, and B. Malmqvist. 2007. Restoring freshwater ecosystems in riverine landscapes: the roles of connectivity and recovery processes. Freshwater Biology 52:589-596.

Jensen, D. W., E. A. Steel, A. H. Fullerton, and G. R. Pess. 2009. Impact of fine sediment on egg-to-fry survival of Pacific salmon: a meta-analysis of published studies. Reviews in Fisheries Science 17:348-359.

Katz, S. L., K. Barnas, R. Hicks, J. Cowen, and R. Jenkinson. 2007. Freshwater habitat restoration actions in the Pacific Northwest: a decade's investment in habitat improvement. Restoration Ecology 15:494-505.

Lackey, R. T. 1998. Fisheries management: integrating societal preference, decision analysis, and ecological risk assessment. Environmental Science and Policy 1:329-335.

LCFRB (Lower Columbia Fish Recovery Board). 2004. Lower Columbia Salmon and Steelhead Recovery and Subbasin Plan, Volume II, Chapter 13: East Fork Lewis (available from http://www.nwcouncil.org/fw/
subbasinplanning/lowerColumbia/plan/2004_05/default.asp) accessed on 11 March 2009.

Lek, S. Uncertainty in ecological models. 2007. Ecological Modelling 207:1-2.

Loomis, J., P. Kent, L. Strange, K. Fausch, and A. Covich. 2000. Measuring the total economic value of restoring ecosystem services in an impaired river basin: results from a contingent valuation survey. Ecological Economics 33:103-117.

McArdle, B. H. \& Anderson, M. J. 2001. Fitting multivariate models to community data: a comment on distance-based redundancy analysis. Ecology 82:290-297.

Merrifield, J. 1997. Sensitivity analysis in benefit-cost analysis: a key to increased use and acceptance. Contemporary Economic Policy 15:82-92.

Naidoo, R., A. Balmford, P. J. Ferraro, S. Polasky, T. H. Ricketts, and M. Rouget. 2006. Integrating economic costs into conservation planning. Trends in Ecology and Evolution 21:681-687.

Newbold, S., J. Siikamaki and M. Clark. 2005. Cost Effective Habitat Protection: The Case of Pacific Salmon. Association of Environmental and Resource Economists Summer Workshop.

Newburn, D., S. Reed, P. Berck, and A. Merenlender. 2005 Economics and land-use change in prioritizing private land conservation. Conservation Biology 19:1411-1420.

Ogden, J. C., J. A. Browder, J. H. Gentile, L. H. Gunderson, R. Fennema, and J. Wang. 1999. Environmental management scenarios: ecological implications. Urban Ecosystems 3:279-303.

Peterson, G. D., G. S. Cumming, and S. R. Carpenter. 2002. Scenario planning: a tool for conservation in an uncertain world. Conservation Biology 17:358-366

Plummer, M. L. 2005. The economic evaluation of stream and watershed restoration projects. Pages 313-330 in P. Roni, editor. Monitoring stream and watershed restoration. American Fisheries Society, Bethesda, Maryland.

Prather, J. W., R. F. Noss, and T. D. Sisk. 2008. Real versus perceived conflicts between restoration of ponderosa pine forests and conservation of the Mexican spotted owl. Forest Policy and Economics 10:140-150.

Prato, T. 2005. Modeling ecological impacts of landscape change. Environmental Modelling and Software 20:1359-1363.

Punt, A. E., A. D. M. Smith, and G. Cui. 2001. Review of progress in the introduction of management strategy evaluation (MSE) approaches in Australia's South East Fishery. Marine and Freshwater Research 52:719-726

Roni, P., K. Hanson, and T. Beedhie. 2008. Global review of the physical and biological effectiveness of stream habitat rehabilitation techniques. North American Journal of Fisheries Management 28:856-890.

Saltelli, A., S. Tarantola and F. Campolongo. 2000. Sensitivity analysis as an ingredient of modeling. Statistical Science 15:377-395.

Santelmann, M. V., D. White, K. Freemark, J. I. Nassauer, J. M. Eilers, K. B. Vache, et al. 2004. Assessing alternative futures for agriculture in Iowa, USA. Landscape Ecology 19:357-374.

Siitonen, P., A. Tanskanen, and A. Lehtinen. 2003. Selecting forest reserves with a multiobjective spatial algorithm. Environmental Science and Policy 6:301-309.

Sklar, F. H., H. C. Fitz, Y. Wu, R. Van Zee, and C. McVoy. 2001. The design of ecological landscape models for Everglades restoration. Ecological Economics 37:379-401.

Song, S. and R. M. M'Gonigle. 2001. Science, power, and system dynamics: the political economy of conservation biology. Conservation Biology 15:980-989.

Spies, T. A., K. N. Johnson, K. M. Burnett, J. L. Ohmann, B. C. McComb, G. H. Reeves, et al. 2007. Cumulative ecological and socioeconomic effects of forest policies in coastal Oregon. Ecological Applications 17:5-17.

Steel, A., A. Fullerton, Y. Caras, M. Sheer, P. Olson, D. Jensen, J. Burke, M. Maher, and P. McElhany. 2008. A spatially explicit decision support system for managing wide ranging species. Ecology and Society 13:50 (available from http://www.ecologyandsociety.org/vol13/iss2/art50/). 
Steel, A., A. Fullerton, Y. Caras, M. Sheer, P. Olson, D. Jensen, J. Burke, M. Maher, D. Miller, and P. McElhany. 2007. A decision-support tool for assessing watershed-scale habitat recovery strategies for ESA-listed salmonids. Lewis River Case Study Final Report. Northwest Fisheries Science Center, Seattle, WA, 190 (available from www.nwfsc.noaa.gov/ research/divisions/ec/wpg/lewis_river.cfm).

Storch, I. 2007. Conservation status of grouse worldwide: an update. Wildlife Biology 13(Suppl. 1):5-12.

Villa, F., L. Tunesi, and T. Agardy. 2002. Zoning marine protected areas through spatial multiple-criteria analysis: the case of the Asinara
Island National Marine Reserve of Italy. Conservation Biology 16: $515-526$.

Waetzold, F., M. Drechsler, C. W. Armstrong, S. Baumgaertner, V. Grimm, A. Huth, C. Perrings, H. P. Possingham, J.F. Shogren, A. Skonhoft, J. Verboom-Vasiljev, and C. Wissel. 2006. Ecological-economic modeling for biodiversity management: Potential, pitfalls, and prospects. Conservation Biology 20:1034-1041.

Wernstedt, K. and C. Paulsen. 1995. Economic and Biological Analysis to Aid System Planning for Salmon Recovery in the Columbia River Basin. Journal of Environmental Management 43:313-331. 